\title{
The Syndromes of Anxiety for Students with Disabilities from the Parents' Perspective in Ajloun Governorate
}

\author{
Haitham Yousef Abu Zaid \\ Department of Special Education, Ajloun University College, Al-Balqa Applied University, Jordan
}

Received February 12, 2020; Revised April 23, 2020; Accepted May 3, 2020

Copyright $\odot 2020$ by authors, all rights reserved. Authors agree that this article remains permanently open access under the terms of the Creative Commons Attribution License 4.0 International License

\begin{abstract}
This study aimed to identify the symptoms of anxiety among students with learning disabilities from the perspective of their parents in Ajloun Governorate. To achieve the objectives of the study, the researcher prepared a questionnaire and distributed it to a sample of (76) parents of students with learning disabilities randomly. Statistical analysis showed that the levels of anxiety among students with learning difficulties ranged between (1.72) to (2.03) with an arithmetic mean of all fields of study. The results showed no statistically significant differences at the level of $(\alpha=0.05)$ in the level of symptoms of anxiety among students with learning disabilities from the parents' point of view in Ajloun Governorate. According to the variables of grade, specifically third and fourth, and gender: male are opposed to female. The study found out that there is average anxiety among students with learning disabilities from their parents' point of view regarding the six areas of anxiety that were studied anaphorically, except for two items in the domain of 'school rejection behaviour': (Students had difficulty in understanding most lessons) and (They feel comfortable staying at home) to a high degree, which is evident that there is a relationship between anxiety and learning difficulties. As well, this level of anxiety among this group of students does not differ in terms of gender or study grade.
\end{abstract}

Keywords Anxiety Symptoms, Students with Learning Disabilities, Parents, Ajloun Governorate

\section{Introduction}

Students' learning difficulties encounter is not new, because, over the years, students with different languages and cultures face difficulties in the learning process. The category of people with learning disabilities among the special education categories received a lot of attention, as it represents almost half of the community of individuals with special needs and is the most prevalent in schools [1,2, 3] and that is why the Ministry of Education in Jordan, as the environment of the current study, opened resource rooms in schools to meet the needs of this category of students. The student from the category of learning disabilities attends regular schools and receives most of his or her education in the regular grade for most grades, and enrolls in Arabic language and mathematics grades in the resource rooms.

In 1963, a conference was held to discuss the issues of students with cognitive disabilities, and the concept of "learning disabilities", initiated by [4]. This concept was adopted and has undergone several developments and changes and thus many definitions have emerged. After returning to many of these definitions and rules $[5,6,7,8$, 9]. The researchers found that there were elements in common as follows:

- $\quad$ The problem of students in this category arises due to the defect in the central nervous system.

- $\quad$ They have a weakness in receiving and processing information.

- They have difficulties in educational skills.

- They have a discrepancy between mental ability (degree of intelligence within the normal range) and academic achievement.

- Excluding other reasons (the existence of cultural or economic deprivation).

Learning difficulties are divided as academic difficulties consisting of reading, writing, mathematics, spelling, and oral expression; developmental difficulties consisting of attention disorders, cognition, remembering, thinking, and language disorders $[10,6,11]$.

Students with learning disabilities, if compared to ordinary ones, are the most at-the-highest level of concern, as $[7,12,13]$ state that the research confirms high levels of anxiety among students with learning disabilities compared to ordinary ones. Symptoms of anxiety include feelings of discomfort, panic attacks, neurological habits or physical 
symptoms such as delusion of illness and physical harm. And the anxiety symptoms also develop sleep and eating disorders, increasing over time. The requirements of the school and the pressure of the examinations increase anxiety and even fear and panic among students with learning disabilities, as well, they feel that there are events in their lives outside their control, and when being exposed to these events, they became afraid. Families and teachers must be aware of these feelings of anxiety because they are real.

Therefore, one of the reasons for the current study is that it seeks to develop an instrument for measuring and diagnosing the emotional aspects of anxiety in students with learning difficulties. As many scales addressed the academic aspect and their developmental difficulties, neglecting the emotional one, this study tried to investigate whether students in the third and fourth grades with learning disabilities have high levels of anxiety and whether this level varies according to the gender and grade variables.

Various studies have dealt with the measurement and diagnosis of academic and developmental learning difficulties. While studies that dealt with measuring and diagnosing the emotional aspect, especially the anxiety aspect in students with learning disabilities, remain little and humble, according to the researcher's knowledge. Thus, this study tried to identify the levels of anxiety among students with learning difficulties in The Jordanian Province of Ajloun, depending on the gender and grade variables. This is the most important possibility to include the anxiety hub, considering it one of the criteria for identifying students with learning disabilities in Jordan.

\subsection{The Objectives of the Study}

The current study aimed at:

1. Identifying the most widespread dimensions of anxiety among students with learning difficulties in the third and fourth grades.

2. Acknowledging the differences in the levels of anxiety between (male and female).

\subsection{The Study Questions}

Specifically, the current study has tried to answer the following questions:

1. What are the anxiety levels among students with learning disabilities from their parents' point of view?

2. Do the levels of anxiety among those with learning disabilities vary according to the student's grades (3rd and 4th) from their parents' point of view?

3. Do the levels of anxiety among students with learning difficulties vary according to the gender of the students (male and female) from their parents' point of view?

\subsection{The Importance of the Study}

Theoretical Importance: This importance comes from the fact that the dependent variable of anxiety plays a key role in academic success, especially among students with learning disabilities. Anxiety constitutes an obstacle to achieving academic and social success for them, and the importance of this study comes from the fact that it provides an instrument to identify indicators in each dimension of anxiety in students with learning disabilities.

Practical Importance: The results of this study are useful in guiding and assisting teachers and parents, and decision-makers in planning and suggesting therapeutic programs for anxiety among students with learning disabilities. As well, it provides the basis for experimental studies that offer and propose programs of early intervention to raise the level of self-confidence in the category of students with learning disabilities.

\subsection{Procedural Definitions of Study Terms}

- Students with Learning Disabilities: They are students who have a neurological disorder that affects their ability to store, process and produce information, and their ability to (developmental difficulties) perception, remembering, paying attention, thinking, and oral language. These effects are shown in the academic difficulties of reading, writing, and mathematics. It is stipulated that these difficulties should not refer to the existence of cultural or economic deprivation. These students are enrolled in Arabic and mathematics grades from the school day in the resource rooms in the schools of the Ministry of Education in the Ajloun Governorate, in which they were detected and diagnosed according to tests accredited by the Ministry of Education.

- $\quad$ Resource Room is an equipped grade attached to the school that provides individual's educational services that comply with the needs of each enrolling student with learning disabilities.

- Anxiety is an emotional condition accompanied by fear, panic or stress and comes from the expectation of a real external risk, being accompanied by several physiological changes [14]. In the current study, anxiety is the degree to which the student receives the scale of anxiety used in this study.

\subsection{The Theoretical Framework of the Study}

That anxiety is part of the natural development of the child. Anxiety and fear are legitimate when the child is facing a scary animal, but they become an unacceptable condition if the degree, duration, and repetition of anxiety and fear increase so that they affect his or her social interaction, development and performance. Anxiety is a condition that outweighs normal fear, including mood, thinking, behaviour, and psychosocial activity disorders.

The term Anxiety originally comes from "Angustia" 
which means the narrowness of getting enough oxygen inside the thorax involuntarily. It is one of the most common psychiatric disorders in the childhood and adulthood stages, affecting $10 \%$ of those in the stage of childhood. Anxiety's symptoms effect (8-11\%) of students of the stage of adolescence. [15].

Psychological anxiety is the most spread disorder among the behavioural and emotional disorders as statistics show that one person among four suffers from anxiety during his or her lifetime. And that there are people who may suffer from anxiety at any time during the year and their percentage is about $(10-17 \%)[15,14]$

Anxiety has multiple causes: genetics, general psychological vulnerability, cultural pressures and the environment, childhood and adolescence problems, painful experiences of the past, stressful life situations, and thinking about the future [15]. Anxiety is classified according to clinical diagnostic criteria made by (DSM-IV)classification as being reported in $[14,16]$ to panic disorder unaccompanied by claustrophobia, panic disorder accompanied by widespread phobias, and widespread phobias of places without having a history of paranoia, specific phobias, social phobia, obsessive-compulsive disorder, post-traumatic stress disorder, and general anxiety disorder.

Many theories are explaining the anxiety; the school of psychoanalysis attributes the anxiety to painful experiences in the human's past. There is a relationship between anxiety and "Id", "Ego", and "Superego". However, the authors of the behavioural theory regarded anxiety as a learning experience and they think the family is the first source of this learning, followed by other social institutions. As for the authors of the cognitive theory, anxiety is a result of patterns of wrong and unadaptable thinking that can be treated by replacing these patterns, which they call cognitive reconstruction [14].

\subsection{The Relationship between Anxiety and Learning Difficulties}

Although not all children with learning disabilities suffer from e-social problems, they are more likely than their regular peers to face these problems, according to the Marjan's study [17] which was applied to a sample of students with learning disabilities in the first year of university. It is expected that students with learning disabilities if being compared to their normal peers suffer from statistically high rates of anxiety.

The acquisition of different academic skills is linked to the development of social behavioural abilities. Anxiety is often associated with failure in academic achievement which leads students with learning disabilities to decrease their self-esteem. Likely, other studies see that one of the emotional and social characteristics of students with learning disabilities is the feeling of lack of self-confidence, causing the feeling of anxiety and tension when performing the task of reading, writing and calculating $[18,19,6,10,7$, $19,15,20]$.

The students with learning disabilities may be more concerned than others as a result of the difficulty of their psychological, educational and social compatibility compared with their peers, the study curriculum, and teaching methods which leads to the exacerbation of their psychological condition and the occurrence of many behavioural problems they have [21]. Patterns of non-consensual behaviour shown by students with learning disabilities include interrupting the speaker, unjustified anxiety or stress, inattention or indifference and poor self-control [22].

The learning difficulties of the students lead to a state of stress and anxiety experienced during their studies as a result of the difficulty of the subject, or the first way the teacher deals with them, or their lack of understanding of many of the terms of the study material. It affects their relationship with family members and friends and their academic achievements. And if they are left without preventive or therapeutic intervention, they will suffer from distress and stress, and thus, leave school and practice anti-social behaviours [21].

Studies, conducted on students with learning disabilities and examined their anxiety, varied. Studies such as $[23,24$, $25,26]$ did various studies aiming at comparing students with learning disabilities with ordinary ones at levels of anxiety. The results were that there were high levels of anxiety among students with learning disabilities if being compared to their normal peers. However, the study of [27] showed that there are no statistically significant differences between students with learning disabilities and normal ones in terms of levels of anxiety.

Other studies such as $[2,15,28]$ showed no statistically significant differences in the levels of anxiety attributed to the grade. The study of $[15,28]$ also indicated that there are statistically significant differences in the severity of anxiety disorder due to the gender variable that goes for the benefit of females. However, the study [28] indicated that there are statistically significant differences in some levels of anxiety in favour of males. On the contrary, the study of $[23,2]$ indicated that there are no statistically significant differences in the severity of anxiety disorder attributed to the gender variable.

Depending on what was presented, the researcher sees a relationship between learning difficulties and anxiety among some students. Accordingly, this study came to try to provide an instrument to detect the levels of anxiety in this category of students. The researcher also believes that what characterized this study is that it has achieved his principle which involves parents, especially in diagnosis through the use of judgments or estimates of the parent in identifying the level of anxiety among students with difficulties because of being more knowledgeable and able to determine the level of anxiety their children have than the external researchers. 


\section{Method and Study Procedures}

\subsection{Study Limitations}

The results of the study are constrained by:

- Academic Limit: The current study is limited to determining the most widespread dimension of anxiety dimensions among students with learning difficulties in the third and fourth grades.

- Spatial Limit: This study is limited to male and female students with learning disabilities in the third and fourth grades who enrolled in the resource rooms in subsidiary schools to the Directorate of Education of Ajloun Province.

- Human Limit: This study was limited to (76) parents of male and female students in the third and fourth grades who enrolled in the resource rooms in public schools, in the Directorate of Education of The Province of Ajloun. These parents of male and female students, with learning disabilities, were selected deliberately.
- Time Limit: the second semester of the school year (2017 - 2018).

The Study Community: - The current study community shall be of all parents of students with learning disabilities and the number is (332) students from the primary third and fourth grades, enrolling in the resource rooms located in the public schools of the Directorate of Education in Ajloun province and distributed to (22) schools in the directorate.

Study Sample: - The study sample consisted of (76) parents of students with learning disabilities who enrolled in the resource rooms. This sample represents the study community, and the parents of students were selected from those whose children have learning difficulties in (6) schools (3 male schools and 3 female schools) during the second semester of the study year of 2017 / 2018. It is worth mentioning that the sample was selected deliberately. And table 1 shows the distribution of the children of the sample members of the parents according to the specific variables of the students.

Table 1. Distribution of children of parents to schools and according to the gender and grade variables

\begin{tabular}{|c|c|c|c|c|c|}
\hline No. & The school's Name & The Grade & The Gender & The Number & $\%$ \\
\hline \multirow{2}{*}{1} & \multirow{2}{*}{ King Nasser's Elementary School for Boys } & Third Grade & Male & 8 & 10.5 \\
\hline & & Fourth Grade & Male & 6 & 7.9 \\
\hline \multirow{2}{*}{2} & \multirow{2}{*}{ Ezzedine Osma's School for Primary for Boys } & Third Grade & Male & 9 & 11.8 \\
\hline & & Fourth Grade & Male & 6 & 7.9 \\
\hline \multirow{2}{*}{3} & \multirow{2}{*}{ Kofranga's Elementary School for Boys } & Third Grade & Male & 5 & 6.6 \\
\hline & & Fourth Grade & Male & 5 & 6.6 \\
\hline \multirow{2}{*}{4} & \multirow{2}{*}{ Al-Amiriya High School for Girls } & Third Grade & Female & 8 & 10.5 \\
\hline & & Fourth Grade & Female & 6 & 7.9 \\
\hline \multirow{2}{*}{5} & \multirow{2}{*}{ The Hashemite's Elementary School for Girls } & Third Grade & Female & 6 & 7.9 \\
\hline & & Fourth Grade & Female & 7 & 9.2 \\
\hline \multirow{2}{*}{6} & \multirow{2}{*}{ Khadija Bint Khuwailed's Mixed Elementary School } & Third Grade & Female & 5 & 6.6 \\
\hline & & Fourth Grade & Female & 5 & 6.6 \\
\hline \multicolumn{4}{|c|}{ The Total } & 76 & 100.0 \\
\hline
\end{tabular}




\subsection{Study Instrument}

To achieve the goal of the study, the researcher prepared a scale of anxiety to be used in the current study. The scale was prepared after looking at some studies and scales related to the subject of the study, the most important studies and scales are those of $[2,23,15,14]$. And then, the terms of the scale were formulated in its initial form consisting of (46) items. These items were divided into six dimensions: ( 6 items) for acute pressures; (9 items) for the anxiety of separation; (6 items) for special concerns; ( 9 items) for the behaviour of the school's rejection; (10 items) for general anxiety; and (6 items) for social anxiety. The parent's answer to the items of the scale was built on his / her estimate of the anxiety level that applies to his son or daughter through the content of the item which complies with the grading triangular scale (always, sometimes, never).

\subsection{Instrument Validity}

The authenticity of the scale was verified in the method of the valid content by displaying the scale in its initial form to ten referees with special education expertise and learning difficulties, educational psychology, psychological and educational guidance, measurement and evaluation of various academic grades, asking them to check the appropriateness and affiliation of the items for each dimension of the scale and the validity of the scale of what was set to be measured. And according to the referees' notes, the linguistic formulation of some items was modified, taking into consideration the items that obtained a consent ratio of $(80 \%)$ or more of the selected referees. Thus, (6) items were deleted, and the scale became in its final form consisting of (40) items distributed over six dimensions (Look at appendix 1) as follows:

1. The severe pressures: the number of items is (6) and the representation of items is (1-6)

2. Separation anxiety: the number of items is (7) and the representation of items is (7-13)

3. Special concerns: the number of items is (5) and the representation of items is (14-18)

4. Behaviour of the school rejection: and the number of items is (8) and the representation of items is (19-26)

5. General concern: the number of items (9) and the representation of items of (27-35)

6. Social anxiety: the number of items is (5) and the representation of items is (36-40)

\subsection{The Instrument Stability}

To ensure the stability of the scale, the repetition method was used, as it was applied to a sample of (20) students, outside the study, who exemplify the primary third and fourth grades. The correlation coefficient for the six dimensions is between $(0.66-0.78)$ and for the scale as a whole $(0.82)$ and this is acceptable for the study purposes.
The stability of internal consistency was calculated using the Cronbach's Alpha equation for all areas of the instrument, ranging from $(0.78-0.76)$ to the overall scale $(0.86)$. This value is also sufficient to consider the instrument fixed and is suitable for using in the current study.

\subsection{Correcting the Instrument}

The scale shall be the final form of (40) items divided into six dimensions, and the parent of the student answers to each item should choose an alternative of the three alternatives: - "always" and "given three degrees", "sometimes" and given two degrees, and "never" and given one degree. And accordingly, the highest score is (120), expressing the presence of anxiety disorder at the highest level within the student at the discretion of the parent. The degree (40) expresses the presence of anxiety disorder at a minimum, and the degree (80) expresses the presence of anxiety disorder at the limit of the hypothetical average of the anxiety scale, considering that the hypothetical average of each item is (2).

\subsection{The Design of the Study}

This study relied on descriptive- approach design and analysis of scientific research methods, namely:

- Descriptive approach: To review the most important literature related to symptoms of anxiety among students with learning difficulties, and previous studies to cover the theoretical aspect of the study.

- Analytical approach: It was used to cover the applied side of this study, through which its questions are answered and its results are drawn based on the study instrument.

The study included the following variables:

A) The independent variables:

1. Class (elementary third and fourth)

2. Gender (male and female)

B) The dependent variables: symptoms of anxiety and the extent of their prevalence among students with learning difficulties and measured through the response to the study instrument.

\subsection{The Statistical Treatment}

It presents extracting results and answering study questions. The researcher used the following statistical methods:

1. Frequencies and percentages of the sample population distribution according to the variables.

2. The mean and standard deviations for answering the first question. 
3. Independent samples T-Test to answer the second and third questions.

\subsection{Study Procedures}

The current study was carried out according to the following steps:

First: The sample was selected from parents of students with learning disabilities who enrolled in the resource rooms in public schools in Ajloun province. The reason for the selection of students from the third and fourth grades is essentially selected by the number of students who have been selected and the attention they receive is early detection of students' learning difficulties.

Second: The researcher held a meeting with a group of parents whose children participated in the study, and during the meeting, the items were discussed with them, to unify the understanding of the items, and this increases the objectivity during the response of the parents on the items of the scale, as it increases confidence more in the statement Collected.

Third: Parents notice and respond on the scale within three weeks to make sure that such behaviour is repeated in their student children.

Fourth: The researcher collected responses on the scale from the concerned schools to unload the responses and conduct appropriate statistical analysis to find out the results.

\section{The Discussion of the Study Results}

Concerning the limits adopted by this study when commenting on the arithmetic mean of variables in the study sample to determine the degree of approval, the researcher identified three levels (high, average, low), depending on the following equation:

Length $=($ The maximum degree of alternative - the minimum degree of alternative) or the number of levels; $(3-1)$ or $3=2$ or $3=0.66$ so the levels are as follows [34]: Low approval score is (1- less than 1.66). The average approval score is (1.66- less than 2.33). High score is (2.33-3.00). Table 2 shows the scale in determining the level of suitability for the Arithmetic mean to be availed when commenting on arithmetic means.

Table 2. The determining Scale of the suitability level of the arithmetic mean

\begin{tabular}{|c|c|}
\hline The arithmetic mean & The Level \\
\hline$(1-$ less than 1.66) & Low \\
\hline$(1.66-$ less than 2.33$)$ & Average \\
\hline$(2.33-3: 00)$ & High \\
\hline
\end{tabular}

The following is a presentation of the study's findings:

- Results related to the first question: What are the levels of anxiety in students with learning disabilities, from their parents' point of view?

To answer this question, mathematical averages and standard deviations of sample individuals' answers to study instrument areas were extracted, Table 3 explains this.

Table 3 shows that the arithmetic mean of anxiety levels among students with learning disabilities ranged from (1.72) to (2.03) with an average rating for all areas of study. The domain of 'school rejection behaviour' was the first place, getting an arithmetic mean (2.03). The third place was for the domains of 'separation anxiety', and 'general anxiety' with arithmetic mean (2.01). The field of 'special concerns' came fourthly with an arithmetic mean (1.89). And in fifth place came the domain of 'severe pressures' with arithmetic mean (1.80). The last place was for ' social 'anxiety' with arithmetic mean (1.72). The arithmetic means of the study instrument as a whole was (1.93) with an average evaluation degree.

This finding can be explained by the fact that the parents of students with learning disabilities were not sufficiently involved in the guidance and training programs on how to deal with their student children. Their training will affect helping their children reduce their anxiety level. Besides, the teachers in the regular classes, while integrating those with learning disabilities with the rest of their colleagues, do not involve the former students in various classrooms and extracurricular activities to enhance their abilities, making them worry both inside and outside the school environment. As a result, they have anxiety and bouts of stress for fear of being asked by the teacher or participating in an educational activity $[12,13]$.

Table 3. The Arithmetic means and standard deviations of sample respondents for study instrument domains are downwardly ranked depending on the arithmetic mean.

\begin{tabular}{|c|c|c|c|c|c|}
\hline The Rank & The Number & The Domain & $\begin{array}{c}\text { The Arithmetic } \\
\text { mean }\end{array}$ & The Standard Deviation & $\begin{array}{c}\text { The Evaluation } \\
\text { Degree }\end{array}$ \\
\hline 1 & 4 & School rejection behaviour & 2.03 & 0.29 & Average \\
\hline 2 & 2 & Separation anxiety & 2.01 & 0.30 & Average \\
\hline 3 & 5 & General concern & 2.01 & 0.35 & Average \\
\hline 4 & 3 & Special concerns & 1.89 & 0.44 & Average \\
\hline 5 & 1 & Severe pressures & 1.80 & 0.61 & Average \\
\hline 6 & 6 & Social anxiety & 1.72 & 0.54 & Average \\
\hline \multicolumn{2}{|r|}{ The instrument as a whole } & 1.93 & 0.27 & Average \\
\hline
\end{tabular}


Although the results of the current study indicated that the level of anxiety level among students with learning disabilities is "average" and this result cannot confirm or deny the correlation between anxiety and learning difficulties, the researcher considers the need to conduct more studies to investigate this aspect in samples of a larger number of students than those with learning disabilities and from geographical areas larger than the area surveyed in this study.

This result seems consistent with $[23,24,25,26]$ and supports the results that there are huge levels of anxiety in students with learning disabilities compared to the average, but this result differs from the result of the study of [27] which showed there are no statistically significant differences between students with learning disabilities and their ordinary peers in terms of anxiety. Arithmetical means and standard deviations of the study's respondents were also extracted on the items of each domain of anxiety levels among individual students with learning disabilities, and tables 4-9 show this.

Table 4 shows that the arithmetic means of the sample members' answers to the 'severe pressures' domain ranged from (1.61) to (2.03). Item 6 (He or she thinks of disturbing things that happen for him or her) came in the first place with arithmetic mean (2.03) and an average rating. On the other hand, the last place was for item 1 ' (He or she causes trouble for the family)' with arithmetic mean (1.61) and a low rating score. The arithmetic means for the field as a whole was (1.80) with an average rating.

This can be explained from the researcher's point of view that the lack of knowledge of parents, brothers, and sisters about the needs of their children with learning disabilities, and therefore, their incapability of meeting these needs and helping them overcome trouble, create such indicators, behaviours, and pressures for the children with disabilities.

Table 5 shows that the arithmetic means of the sample members' answers to the items of the 'separation anxiety' field ranged from (1.63) to (2.49). The first place was for item (5) 'He or she likes his or her sisters' with an arithmetic mean of (2.49) and a high rating. However, the last place was for item (6) "He or she feels being non-beloved by the parents" with arithmetic mean (1.63) and a low rating. And the arithmetic means for the field as a whole was (2.01) with an average rating.

The researcher can attribute the reason for this result to the fluctuation in treatment by family members, and therefore to the fluctuation in the emotional state of students with learning difficulties in terms of his / her feelings such as, love obedience, and distress.

Table 4. Arithmetic means and standard deviations of individuals' answers sample to 'severe pressures'-domain items are downwardly ordered following the arithmetic mean

\begin{tabular}{|c|c|c|c|c|c|}
\hline The Rank & The Number & The Item & $\begin{array}{l}\text { The Arithmetic } \\
\text { mean }\end{array}$ & $\begin{array}{l}\text { The Standard } \\
\text { Deviation }\end{array}$ & $\begin{array}{c}\text { The Evaluation } \\
\text { Degree }\end{array}$ \\
\hline 1 & 6 & $\begin{array}{l}\text { He or she thinks about annoying things that } \\
\text { happen to him or her. }\end{array}$ & 2.03 & 0.69 & Average \\
\hline 2 & 3 & He or she does a lot of bad things. & 1.86 & 0.80 & Average \\
\hline 3 & 2 & He or she annoys brothers without feeling so. & 1.84 & 0.80 & Average \\
\hline 4 & 5 & $\begin{array}{l}\text { He or she thinks of causing evil things to } \\
\text { relatives. }\end{array}$ & 1.79 & 0.66 & Average \\
\hline 5 & 4 & He or she breaks things down. & 1.66 & 0.78 & Average \\
\hline 6 & 1 & He or she causes trouble for the family. & 1.61 & 0.78 & Low \\
\hline \multicolumn{3}{|c|}{ The domain of " severe pressures" as a whole } & 1.80 & 0.61 & Average \\
\hline
\end{tabular}

Table 5. Arithmetic means and standard deviations of sample individuals' answers to 'separation anxiety' domain items are downwardly according to the arithmetic mean.

\begin{tabular}{|c|c|l|c|c|c|}
\hline $\begin{array}{c}\text { The } \\
\text { Rank }\end{array}$ & $\begin{array}{c}\text { The } \\
\text { Number }\end{array}$ & \multicolumn{1}{|c|}{ The Item } & $\begin{array}{c}\text { The Arithmetic } \\
\text { mean }\end{array}$ & $\begin{array}{c}\text { The Standard } \\
\text { Deviation }\end{array}$ & $\begin{array}{c}\text { The Evaluation } \\
\text { Degree }\end{array}$ \\
\hline 1 & $\mathbf{5}$ & He or she loves his or her brothers & 2.49 & 0.77 & High \\
\hline 2 & $\mathbf{3}$ & He or she is an obedient person at home & 2.41 & 0.68 & High \\
\hline 3 & $\mathbf{1}$ & $\begin{array}{l}\text { He or she feels like an important person } \\
\text { within the family }\end{array}$ & 2.14 & 0.76 & Average \\
\hline 4 & $\mathbf{2}$ & He or she behaves badly inside the house & 1.83 & 0.79 & Average \\
\hline 5 & $\mathbf{7}$ & He or she doesn't talk a lot with the family & 1.78 & 0.64 & Average \\
\hline 6 & $\mathbf{4}$ & He or she feels upset because of the family & 1.76 & 0.73 & Low \\
\hline 7 & $\mathbf{6}$ & $\begin{array}{l}\text { He or she believes of being non-beloved by } \\
\text { the parents }\end{array}$ & 1.63 & 0.76 & Average \\
\hline \multicolumn{2}{|l}{ The domain of "separation anxiety" as a whole } & 2.01 & 0.30 & Average \\
\hline
\end{tabular}


Table 6. Arithmetic means and standard deviations of sample individuals' answers to 'special concerns' domain- items that are ranked downwardly by the arithmetic mean

\begin{tabular}{|c|c|l|c|c|c|}
\hline The Rank & $\begin{array}{c}\text { The } \\
\text { Number }\end{array}$ & \multicolumn{1}{|c|}{ The item } & $\begin{array}{c}\text { The Arithmetic } \\
\text { mean }\end{array}$ & $\begin{array}{c}\text { The Standard } \\
\text { Deviation }\end{array}$ & $\begin{array}{c}\text { The Evaluation } \\
\text { Degree }\end{array}$ \\
\hline 1 & 3 & $\begin{array}{l}\text { He or she complains about walking in empty } \\
\text { places }\end{array}$ & 2.11 & 0.58 \\
\hline 2 & 1 & He or she feels afraid of sitting in high places & 1.88 & 0.83 & Average \\
\hline 3 & 2 & He or she feels afraid of being in dark places & 1.86 & 1.83 & 0.63 \\
\hline 4 & 4 & He or she feels afraid of dogs and cats & 1.76 & 0.70 \\
\hline 5 & 5 & He or she feels afraid of insects & 1.89 & Average & Average \\
\hline \multicolumn{2}{|l}{ The domain of " special concerns" as a whole } & Average \\
\hline
\end{tabular}

Table 7. Arithmetic means and standard deviations of sample members' answers to 'school rejection behaviour' domain -items are downwardly ordered following the arithmetic mean

\begin{tabular}{|c|c|c|c|c|c|}
\hline The Rank & The Number & The item & $\begin{array}{l}\text { The Arithmetic } \\
\text { mean }\end{array}$ & $\begin{array}{c}\text { The Standard } \\
\text { Deviation }\end{array}$ & $\begin{array}{c}\text { The Evaluation } \\
\text { Degree }\end{array}$ \\
\hline 1 & 7 & $\begin{array}{l}\text { It is difficult for him or her to understand most of } \\
\text { the lessons. }\end{array}$ & 2.36 & 0.48 & High \\
\hline 2 & 5 & He or she feels comfortable to stay at home & 2.34 & 0.48 & High \\
\hline 3 & 8 & $\begin{array}{l}\text { He or she frequently fights with his or her } \\
\text { classmates at school. }\end{array}$ & 2.21 & 0.77 & Average \\
\hline 4 & 6 & He or she hates going to school. & 2.18 & 0.71 & Average \\
\hline 5 & 2 & He or she prefers playing at home. & 2.01 & 0.77 & Average \\
\hline 6 & 4 & The school arouses his or her fears. & 1.76 & 0.81 & Average \\
\hline 7 & 1 & $\begin{array}{l}\text { He or she feels that classmates make fun of him } \\
\text { or her. }\end{array}$ & 1.70 & 0.75 & Average \\
\hline 8 & 3 & He or she feels scared of contact with students. & 1.70 & 0.78 & Average \\
\hline \multicolumn{3}{|c|}{ The domain of "school rejection behaviour" as a whole } & 2.03 & 0.29 & Average \\
\hline
\end{tabular}

Table 6 shows that the arithmetic means of the sample members' answers to the 'special concerns' domain items ranged from (1.76) to (2.11) with an average rating of all items. The first place was for item (3) ' he or she complains about walking in empty places ' with arithmetic mean (2.11). In the last place came item (5) 'he or she feels afraid of insects' with arithmetic mean (1.76). And the arithmetic means for the field as a whole (1.89) with an average rating.

The researcher explains this finding that the problem of the student with learning difficulties does not start and end at the door of the class, but affects all aspects of his or her life [7]. Thus, he or she has more feelings of fear compared to those of his or her age. On the contrary, ordinary children find pleasure in playing with dogs, cats, and insects such as butterflies while those with learning difficulties are afraid of them.

Table 7 shows that the arithmetic means of the sample members' answers to the 'school rejection behaviour' domain- items ranged from (1.70) to (2.36). Item (7) ' it is difficult for him or her to understand most of the lessons' came in the first place. The Last place was, evenly, for item 3 'he or she feels scared of contact with students' and item (1) 'He or she feels that school classmates make fun of him or her' with an arithmetic mean of (1.70). The arithmetic means for the whole field was (2.03) with an average rating.

This result can be explained from the researcher's point of view as the concept of "the self" cannot be given in a medical injection to the student but is taught and this comes through the exposure of the individual to experience success Johns [7]. As well, one of 'the self 'aspects is the academic concept and when the academic-self-concept is low, behaviours are anaphorically mentioned in the items of this field, such as the lack of acceptance of the school and classmates in the school appear. 
Table 8. Arithmetic means and standard deviations of sample individuals' answers to 'general concern' domain-items are downwardly ordered in terms of the arithmetic mean.

\begin{tabular}{|c|c|c|c|c|c|}
\hline The Rank & The Number & The Item & $\begin{array}{l}\text { The Arithmetic } \\
\text { mean }\end{array}$ & $\begin{array}{c}\text { The Standard } \\
\text { Deviation }\end{array}$ & $\begin{array}{c}\text { The Evaluation } \\
\text { Degree }\end{array}$ \\
\hline 1 & 2 & He or she is a hesitant person. & 2.25 & 0.73 & Average \\
\hline 2 & 3 & He or she feels tired while doing deeds. & 2.20 & 0.78 & Average \\
\hline 3 & 5 & He or she feels upset in the new situations. & 2.18 & 0.80 & Average \\
\hline 4 & 1 & $\begin{array}{l}\text { He or she feels upset when his or her desire is } \\
\text { not fulfilled. }\end{array}$ & 2.14 & 0.76 & Average \\
\hline 5 & 4 & $\begin{array}{l}\text { He or she is extremely worried about being in } \\
\text { charge }\end{array}$ & 2.08 & 0.80 & Average \\
\hline 6 & 8 & His or Her temperament is easily disturbed. & 2.07 & 0.41 & Average \\
\hline 7 & 6 & He or she is quickly provoked. & 1.74 & 0.68 & Average \\
\hline 8 & 9 & He or she is quickly in tears. & 1.74 & 0.66 & Average \\
\hline 9 & 7 & He or she hesitates to participate with others. & 1.72 & 0.58 & Average \\
\hline \multicolumn{3}{|c|}{ The domain of " general concern" as a whole } & 2.01 & 0.35 & Average \\
\hline
\end{tabular}

Table 9. Arithmetic means and standard deviations of sample individuals' answers to 'social anxiety ' domain-items are downwardly ordered in terms of the arithmetic mean

\begin{tabular}{|c|c|l|c|c|c|}
\hline The Rank & The Number & \multicolumn{1}{|c|}{ The Item } & $\begin{array}{c}\text { The Arithmetic } \\
\text { mean }\end{array}$ & $\begin{array}{c}\text { The Standard } \\
\text { Deviation }\end{array}$ & $\begin{array}{c}\text { The Evaluation } \\
\text { Degree }\end{array}$ \\
\hline 1 & 2 & $\begin{array}{l}\text { He or she talks that their classmates don't } \\
\text { like him or her. }\end{array}$ & 1.84 & 0.85 \\
\hline 2 & 4 & $\begin{array}{l}\text { He or she feels tense when he or she is in } \\
\text { the exam. }\end{array}$ & 1.78 & 0.64 \\
\hline 3 & 5 & He or she is afraid of taking exams. & 1.70 & 0.69 \\
\hline 4 & 3 & $\begin{array}{l}\text { He or she feels ashamed while talking to } \\
\text { others. }\end{array}$ & 1.67 & 0.60 \\
\hline 5 & 1 & $\begin{array}{l}\text { He or she finds it difficult to make a } \\
\text { friendship with others. }\end{array}$ & 1.61 & 0.69 \\
\hline
\end{tabular}

Table 8 shows that the arithmetic means of the sample members' answers to the 'general concern' domain-items ranged from (1.72) to (2.25) with an average rating. The first place was for item (2) ' he or she is a very hesitant person', getting arithmetic mean (2.25) with an average rating. Unlikely, item (7) ' he or she hesitates to participate with others' came lastly with arithmetic mean (1.72). The arithmetic means for the domain as a whole was (2.01) with an average rating.

The researcher explains this finding that students with learning difficulties, during growing up, develop emotional challenges by showing emotional problems [5, 7, 29]. Anxiety, hesitation, and withdrawal are often associated with failure in academic achievement; the student is reluctant to share with others, because he or she always thinks about the opinion of those around him or her, showing increasing anger due to the sensation of inferiority as a result of his or her inability to learn academically.

Table 9 shows that the arithmetic means of respondents' answers to 'social anxiety' have ranged from (1.61) to (1.84). Item (2) "he or she talks that colleagues do not like him or her" came in the first place with arithmetic mean
(1.84) and an average degree. However, the last place was for item (1) "he or she finds difficulty in forming a friendship with others", getting low arithmetic mean (1.61). The arithmetic means for the field as a whole was (1.72) with an average degree.

The researcher explains this finding that students with learning disabilities show a lower level of social skills if being compared to their ordinary peers [7, 29]. And social skills, such as establishing a good relationship with others, are an influential factor in the psychological and emotional components of the student.

The results related to the second question: Do the levels of anxiety among those with learning disabilities vary depending on the students' grades, third or fourth, from their parents' point of view? To answer this question, the arithmetic means and standard deviations of the respondents in the study sample were extracted from all domains of anxiety levels in those with learning disabilities, and the Independent Samples of T-Test was applied to the study areas and the instrument as a whole depending on the (grade) variable as table 10 explains it. 
Table 10. Results of applying the Independent Samples T-Test to the study domains and the instrument as a whole depending on the grade variable

\begin{tabular}{|c|c|c|c|c|c|}
\hline The Domain & The Level & The Arithmetic mean & The Standard Deviation & $\mathbf{T}$ & Statistical significance \\
\hline \multirow{2}{*}{ Severe pressures } & Third & 1.74 & 0.60 & - & \multirow{2}{*}{0.44} \\
\hline & Fourth & 1.85 & 0.63 & 0.78 & \\
\hline \multirow{2}{*}{ Separation anxiety } & Third & 2.02 & 0.32 & \multirow[b]{2}{*}{0.27} & \multirow{2}{*}{0.79} \\
\hline & Fourth & 2.00 & 0.29 & & \\
\hline \multirow{2}{*}{ Special concerns } & Third & 1.98 & 0.50 & \multirow{2}{*}{1.84} & \multirow{2}{*}{0.07} \\
\hline & Fourth & 1.79 & 0.36 & & \\
\hline \multirow{2}{*}{ School rejection behaviour } & Third & 2.03 & 0.29 & - & \multirow{2}{*}{0.85} \\
\hline & Fourth & 2.04 & 0.30 & 0.19 & \\
\hline \multirow{2}{*}{ General concern } & Third & 2.04 & 0.36 & \multirow{2}{*}{0.76} & \multirow{2}{*}{0.45} \\
\hline & Fourth & 1.98 & 0.34 & & \\
\hline \multirow{2}{*}{ Social anxiety } & Third & 1.72 & 0.48 & - & \multirow{2}{*}{0.97} \\
\hline & Fourth & 1.72 & 0.61 & 0.04 & \\
\hline \multirow{2}{*}{ The instrument as a whole } & Third & 1.94 & 0.28 & \multirow{2}{*}{0.32} & \multirow{2}{*}{0.75} \\
\hline & Fourth & 1.92 & 0.27 & & \\
\hline
\end{tabular}

Table 11. Results of applying the Independent Samples T-Test to the study domains and the instrument as a whole depending on the (gender) variable

\begin{tabular}{|c|c|c|c|c|c|}
\hline The Domain & The Level & The Arithmetic mean & The Standard Deviation & $\mathbf{T}$ & Statistical significance \\
\hline \multirow{2}{*}{ Severe pressures } & Male & 1.73 & 0.58 & - & \multirow{2}{*}{0.37} \\
\hline & Female & 1.85 & 0.63 & 0.91 & \\
\hline \multirow{2}{*}{ Separation anxiety } & Male & 1.99 & 0.31 & - & \multirow{2}{*}{0.64} \\
\hline & Female & 2.02 & 0.31 & 0.47 & \\
\hline \multirow{2}{*}{ Special concerns } & Male & 1.95 & 0.51 & \multirow{2}{*}{1.18} & \multirow{2}{*}{0.24} \\
\hline & Female & 1.83 & 0.37 & & \\
\hline \multirow{2}{*}{ School rejection behaviour } & Male & 1.98 & 0.26 & - & \multirow{2}{*}{0.14} \\
\hline & Female & 2.08 & 0.31 & 1.48 & \\
\hline \multirow{2}{*}{ General concern } & Male & 2.01 & 0.37 & - & \multirow{2}{*}{0.94} \\
\hline & Female & 2.02 & 0.34 & 0.07 & \\
\hline \multirow{2}{*}{ Social anxiety } & Male & 1.67 & 0.49 & - & \multirow{2}{*}{0.49} \\
\hline & Female & 1.76 & 0.59 & 0.69 & \\
\hline \multirow{2}{*}{ The instrument as a whole } & Male & 1.91 & 0.27 & - & \multirow{2}{*}{0.51} \\
\hline & Female & 1.95 & 0.28 & 0.67 & \\
\hline
\end{tabular}

Table 10 shows no statistically significant differences at the level of indication $(\alpha \leq 0.05)$ between the responses of sample members to the study domains and the instrument as a whole depending on the grade variable. The $T$ values were not statistically significant. This result can be explained that there is no significant difference in age between students in the third and fourth grades, i.e. they are of the same age group, so there is no statistical signifying effect of the change of grade. Students in these grades are, academically also called students of the first cycle of primary education and this is further evidence of convergence in the stage of cognitive development as well as convergence in emotional and social growth.

This finding is consistent with the study of $[2,15,28]$, in which they concluded that there were no statistically significant differences due to the grade change.

Results related to the third question: Do the levels of anxiety among students with learning disabilities vary according to the gender of the student (male, female) from their parents' point of view? To answer this question, arithmetic means and standard deviations of the study sample members were extracted from all anxiety levels among students with learning disabilities. And the Independent Samples T-Test was applied to the study areas 
and the instrument as a whole depending on the (gender) variable and table 11 explains it.

Table 11 shows no statistically significant differences at the level of indication $(\alpha \leq 0.05)$ between the responses of sample members to the study domains and the instrument as a whole depending on the gender variable. The $T$ values were not statistically significant.

This finding can be explained by the fact that male and female students with learning disabilities were similarly raised and prepared by the family and school. Females have high levels of scientific, social and psychological competence to prepare them as mothers for the future.

This finding is consistent with a study of [23] in which they found no statistically significant differences among students with learning disabilities about domains and levels of anxiety attributable to the gender variable. However, the outcomes of the current study differ from the studies of [15, 30] as the latter results indicated that there were statistically significant differences in anxiety levels due to the gender variable.

\section{Recommendation}

Based on the former findings, the study recommends the following:

1. There should be a focus on the role of families and the preparation of training programs for this role which serve psychological preparation to prevent and alleviate anxiety among students with learning disabilities.

2. Teachers use all means that contribute to the increase in students' ability to avoid anxiety.

3. Further studies should be conducted to investigate this aspect (anxiety) in larger samples and other age groups of students with learning disabilities.

4. The study recommends researchers conduct studies and propose training programs that will improve the emotional, psychological and social aspects of students with learning disabilities.

\section{Conclusions}

At the end of this study, the researcher concluded that there is average anxiety among students with learning disabilities from their parents' point of view regarding the six areas of anxiety that were studied anaphorically, except for two items in the domain of 'school rejection behaviour': (Students had difficulty in understanding most lessons) and (They feel comfortable staying at home) to a high degree, which is evidence that there is a relationship between anxiety and learning difficulties. As well, this level of anxiety among this group of students does not differ in terms of gender or study grade.

\section{Appendix (1)}

The Final form of anxiety scale for students with learning disabilities:

The Student's Respectful Parent:

Greetings. Here is a set of common items that constitute a test to assess the prevalence of anxiety among students with learning disabilities, so please kindly answer them relying on your mere observation of your student-child. Note that there is no correct answer and another wrong, as well, please do not leave any words unanswered so that the researcher can benefit from your answers that, in turn, will be completely confidential and will only be used for scientific research purposes. If the item applies to the student, put the sign $(\mathrm{x})$ in the place you see it applies to your child's status as in the following example:

\begin{tabular}{|c|c|c|c|c|}
\hline \multirow{2}{*}{ Number } & \multirow{2}{*}{ The item } & \multicolumn{3}{|c|}{ The degree to which the item applies } \\
\cline { 3 - 5 } & & Always & Sometimes & Never \\
\hline 1 & He or she is afraid to sit in dark places. & & & $\mathrm{X}$ \\
\hline
\end{tabular}

1. The grade in which the student is studying: The third grade

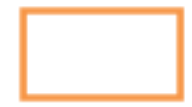

The fourth grade

\section{Student's Gender: Male}

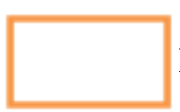

Female

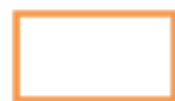

Thank you very much for your co-operation with the researcher Dr. Haitham Yousef Abu Zaid, Ajloun University College - Balqa' Applied University. 


\begin{tabular}{|c|c|c|c|c|}
\hline \multirow{2}{*}{ Number } & \multirow{2}{*}{ The items } & \multicolumn{3}{|c|}{ The degree to which the item applies } \\
\hline & & Always & Sometimes & Never \\
\hline 1 & He or she thinks about annoying things that happen to him or her. & & & \\
\hline 2 & He or she does a lot of bad things. & & & \\
\hline 3 & He or she annoys brothers without feeling so. & & & \\
\hline 4 & He or she thinks of causing evil things to relatives. & & & \\
\hline 5 & He or she breaks things down. & & & \\
\hline 6 & He or she causes trouble for the family. & & & \\
\hline 7 & He or she loves his or her brothers & & & \\
\hline 8 & He or she is an obedient person at home & & & \\
\hline 9 & He or she feels an important person within the family & & & \\
\hline 10 & He or she behaves badly inside the house & & & \\
\hline 11 & He or she doesn't talk a lot with the family & & & \\
\hline 12 & He or she feels upset because of the family & & & \\
\hline 13 & He or she believes of being non-beloved by the parents & & & \\
\hline 14 & He or she complains about walking in empty places & & & \\
\hline 15 & He or she feels afraid of sitting in high places & & & \\
\hline 16 & He or she feels afraid of being in dark places & & & \\
\hline 17 & He or she feels afraid of dogs and cats & & & \\
\hline 18 & He or she feels afraid of insects & & & \\
\hline 19 & It is difficult for him or her to understand most of the lessons. & & & \\
\hline 20 & He or she feels comfortable to stay at home & & & \\
\hline 21 & He or she frequently fights with his or her classmates at school. & & & \\
\hline 22 & He or she hates going to school. & & & \\
\hline 23 & He or she prefers playing at home. & & & \\
\hline 24 & The school arouses his or her fears. & & & \\
\hline 25 & He or she feels that classmates make fun of him or her. & & & \\
\hline 26 & He or she fears of contact with students. & & & \\
\hline 27 & He or she is a hesitant person. & & & \\
\hline 28 & He or she feels tired while doing deeds. & & & \\
\hline 29 & He or she feels upset in the new situations. & & & \\
\hline 30 & He or she feels upset when his or her desire is not fulfilled. & & & \\
\hline 31 & He or she is extremely worried about being in charge & & & \\
\hline 32 & His or Her temperament is easily disturbed. & & & \\
\hline 33 & He or she is quickly provoked. & & & \\
\hline 34 & He or she is quickly in tears. & & & \\
\hline 35 & He or she hesitates to participate with others. & & & \\
\hline 36 & He or she talks that their classmates don't like him or her. & & & \\
\hline 37 & He or she feels tense when he or she is in the exam. & & & \\
\hline 38 & He or she is afraid of taking exams. & & & \\
\hline 39 & He or she feels ashamed while talking to others. & & & \\
\hline 40 & He or she finds it difficult to make a friendship with others. & & & \\
\hline
\end{tabular}




\section{REFERENCES}

[1] Abu Arab, Majid. (2017). Self-identification and its relationship to depression in a sample of children with reading difficulty learning. Journal of Scientific Research in Education, (18), 75-89.

[2] Al-Samadi, Hussein and Al-Shabul, Muhannad. (2015). Assessing the levels of anxiety among students with learning disabilities regarding learning in a Jordanian sample. The Journal of the Islamic University of Educational and Psychological Studies,. 23, (4), 135-154.

[3] Learner, Janet and Johns, Beverley. (2000). Learning disabilities: Theories, diagnosis, and teaching strategies, ( $8^{\text {th }}$ Ed.) Boston: Houghton Mifflin Company.

[4] Kirk, Samuel. (1962). Educating exceptional children. Boston: Houghton Mifflin.

[5] Al-Bataina Osama, et al. (2018). Theoretical and practical learning difficulties. Amman: Dar Al-Maseera for Publishing and Distribution.

[6] Ghneim, Adel. (2016). Treatment programs for learning disabilities. Amman: Dar Al-Maseera for Publishing and Distribution.

[7] Learner, Janet and Johns, Beverley. (2014). Learning difficulties and minor disabilities related to the characteristics and strategies of teaching and modern orientations, translated by Suha Al Hassan. Amman: Dar Al-Fikr for Publishing and Distribution.

[8] Hallahan, Danial and Kauffman, James. (2013). Students with special needs, translated by Mohammed Al- Jabri. Amman: Dar al-Fikr Publishers and Distributors.

[9] Al-Wakfi, Radhi. (2012). Theoretical and applied learning difficulties. Amman: Dar Al-Maseera for Publishing and Distribution.

[10] Khasawnah, Mohammed, et al. (2016). The entrance to learning difficulties. Amman: Dar Al-Fikr for Publishing and Distribution.

[11] Salem, Mahmoud, et al. (2013). Learning Disabilities: Diagnosis and Treatment. Amman: Dar Al-Fikr Publishers and Distributors.

[12] Shaheen, Heyam. (2012). Self-efficacy is an entry point for reducing symptoms of anxiety and improving educational achievement in a Sample of Students with Learning Disabilities. Damascus University Journal, 28, (4), 147-201.

[13] Greenhill, L. (2000). Learning disabilities: Implication for psychiatric treatment. Washington: American Psychiatric Press.

[14] Al-Kayed, Zain. (2010). Deriving Jordanian criteria on the scale of the psychological profile of children and adolescents in detecting behavioural and emotional disorders for (2-17) years old. Unpublished Doctoral Thesis. Amman: University of Jordan.

[15] Al-Qubtan, Jenan. (2011). Some mental disorders among students with learning disabilities in primary educational schools in Muscat Province. Unpublished Master's Thesis. Oman: Nizwa University.

[16] Wilmshurst, 1 (2005). Essentials of Child Psychopathology. $\left(1^{\text {st }} \mathrm{Ed}\right)$. Farmington Hills: Green Haven Press.

[17] Marjan, S. (2005). Adjustment of college students with learning disabilities. Dissertation Abstracts: International Dissertation, 66, (4), 15-23.

[18] Al-Dahini, Rasha. (2017). Dyslexia and the characteristic behavioural indicators of third graders. Unpublished Master's Thesis, Islamic University, Gaza.

[19] Al-Samadi, Ali and Al-Shamali, Sayah. (2017). Modern concepts in learning difficulties. Amman: Dar Al-Maseera for Publishing and Distribution.

[20] Al-Qamish, Mustafa and Ma'aita, Khalil. (2012). Psychology of children with special needs. Amman: Dar Al- Maseera for Publishing and Distribution.

[21] Al-Khatib, A'kif. (2009). Source room as an educational alternative for people with special needs: A practical guide for teachers of learning disabilities. Irbid: The World of Modern Books.

[22] Al-Kabbali, Yahya. (2008). Behavioural and emotional disorder. Amman: Dar Attareeq for Publishing and Distribution.

[23] Al-Zayat, Fathi. (2008). Contemporary issues in learning difficulties. Cairo: University Publishing House.

[24] Alesi, M, Reppo, G, and Pepi, A. (2014). Depression, anxiety at school and self-esteem in children with learning disabilities. Journal of Psychological Abnormalities in children, 3, (3), 10-15.

[25] Balouti, A. (2013). Comparison of psychological- mental state between children with learning disabilities and normal children. International Journal of Psychology and Behavioural Research, 2, (3), 126-131.

[26] Carroll, J and lles, J. (2006). An assessment of anxiety levels in dyslexic students in higher education. British Journal of Educational Psychology, 76, (3), 651-622.

[27] Mercer, K. (2004). Relations of Self-Efficacy to Symptoms of Depression and Anxiety in Adolescents with Learning Disabilities. Pro Quest Dissertations and Thesis, section 2500, part, 222.

[28] Al-A'lami, Ibtisam. (2010). Blood types and some psychological disorders in a sample of students with learning difficulties and of normal peers in the primary stage in Mecca. Unpublished Doctoral Letter, Um al-Qura University, Saudi Arabia.

[29] Mahmoud, Aman, Saber, Samia. (2004). Some psychological and behavioural characteristics of students with learning disabilities. Arab Childhood Magazine, 5, (19). Reterived from www.arabpsynet.com

[30] Al-Meqdad, Qais, et al. (2011). The level of social skills of ordinary children and children with learning disabilities in Jordan. The Jordanian Journal of Educational Sciences, 7, (3), 253-270.

[31] Li, H M.R. (2007). Assessing fears and related anxieties in children and adolescents with learning disabilities or mild mental retardation. Academic journal, 39, (1), 45-457. 